\title{
ANALISIS PENGARUH SENSUAL MARKETING TERHADAP MINAT BELI PADA PRODUK CLOTHING LINE "BERAK" DI INSTAGRAM
}

\author{
Jimmy Ary Pratama \\ jimmyarypratama@gmail.com \\ Universitas Ahmad Dahlan \\ Fitroh Adhilla \\ fitauad@yahoo.com \\ Universitas Ahmad Dahlan
}

\begin{abstract}
ABSTRAK
This research is to find out whether there is a significant influence between sensual marketing strategies that are triggered by a model, body language, and nature how to communicate with buying interest in "Shit" clothing line products in the media instagram, both partially and simultaneously. The population of this research is the students of private universities in the city Yogyakarta has never seen a display of defecated Instagram. Samples in research this amounted to 80 respondents where the determination using accidental techniques sampling and purposive sampling. Testing using statistical tests multiple linear regression analysis. Partially, the statistical test used is a test $t$ and simultaneously using the $F$ test. Data collection techniques with questionnaire distribution. As for testing the instrument uses test validity and reliability. From the analysis it can be concluded that partially sensual strategy marketing which consists of model, body language, and method variables communicating significantly. Whereas simultaneously the strategy sensual marketing also has a significant influence on buying interest.
\end{abstract}

Keywords: Sensual Marketing; Purchase Interest.

\section{PENDAHULUAN}

Pada era globalisasi ini, kita sering mendengar istilah online marketing atau pemasaran online. Pemasaran online adalah suatu proses penyampaian produk kepada konsumen yang memanfaatkan jaringan internet. Online marketing lambat laun menjelma menjadi dunia yang sangat menggiurkan bagi para pemasar untuk memasarkan produknya. Ada banyak faktor yang menyebabkan online marketing bisa sangat berkembang pesat, di antaranya adalah biaya promosi dan pemasaran yang sangat terjangkau, serta kecenderungan para konsumen yang mulai percaya dan beralih ke online marketing. Menurut Hanggono (2015) internet marketing merupakan proses dalam membangun dan mempertahankan customer relationship melalui aktivitas online yang merupakan produk, pertukaran ide, dan jasa yang dapat memenuhi kepuasan pelanggan.

Dalam pemasaran modern, dunia internet atau online sudah menjadi hal lumrah bila digunakan sebagai media pemasaran. Dalam online marketing memiliki banyak sub atau bagian-bagian yang bisa sangat mudah dimanfaatkan sebagai media pemasaran dan sangat sering kita jumpai. Salah satu yang sudah akrab di telinga kita adalah sosial media, sosial media akhir-akhir ini merupakan media yang sedang banyak digunakan para kaum muda dan tak jarang kaum dewasa pun tak mau ketinggalan dari fenomena maha dahsyat di abad ini.

Menurut Utami (2011) sosial media adalah sebuah media online dimana para 
penggunanya bisa dengan mudah berpartisipasi, berbagi, dan menciptakan isi meliputi blog, sosial network atau jejaring sosial, wiki, forum dan dunia virtual. Blog, jejaring sosial dan wiki mungkin merupakan bentuk media sosial yang paling umum digunakan oleh masyarakat di seluruh dunia.

Ada berbagai macam akun-akun sosial media yang sangat akrab digunakan, terkadang para penggunanya menganggap sosial media sebagai dunia kedua mereka, atau bahkan menganggap sebagai dunia utama yang tak mungkin bisa ditiggalkan. Kenapa dikatakana ini adalah sebuah fenomena maha dahsyat? karena sudah menjadi rahasia umum dan bahkan semua orang tahu bahwa internet, dan gadget sebagai alat atau media untuk mengakses internet bisa merubah sikap, perilaku, serta polah hidup penggunanya. Ada pepatah modern yang akhir-akhir ini sering kita lihat di internet yaitu, "mendekatkan yang jauh dan menjauhkan yang dekat" mungkin ini bukan sekedar pepatah kosong sebagai hiburan belaka, ini adalah fakta yang nyata, suatu fenomena yang tidak kita sadari dan atau bahkan pura-pura tidak kita sadari.

Di internet dan khususnya di sosial media, kita bisa melakukan apa saja dalam genggaman kita. Kita bisa bertatap langsung dengan kerabat, berbagi moment bahagia, bernostalgia dengan rekan sejawat, bertukar fikiran, berbelanja, atau bahkan kita bisa membuat sebuah forum besar tanpa bertatap muka. Kehadiranya yang tidak kita sadari namun nyatanya kita ikut menikmati dan lambat laun menjadi kebutuhan sehari-hari, maka tidak ada alasan untuk kita juga mengatakan bahwa ini adalah fenomena maha dahsyat.

Karena keajaiban internet yang mampu memikat siapa saja, maka sudah barang tentu pemasar yang jelih tidak akan mungkin melewatkan kesempatan ini begitu saja, "dimana ada gula disitu ada semut" adalah sebuah pepatah kuno yang cukup moderen untuk menggambarkan fenomena ini. Di sosial media yang sedang ramai-ramainya digandrungi masyarakat merupakan media pemasaran online yang sangat menggiurkan bagi pemasar saat ini.

Apalah arti media yang efektif jika proses atau cara penyampaian tidak dilakukan dengan benar. Maka inovasi pun mulai memainkan peran liarnya guna memikat hati target pasarnya. Marketing yang memiliki tugas utama dalam hal ini harus bisa merumuskan suatu rumusan yang jitu guna target pasar yang di inginkan bisa terpenuhi. Perlu rumusan yang memiliki harmonisasi, dalam hal ini adalah harmonisasi antar media yang digunakan dan strategi yang tepat untuk penggunaan media tersebut, sehingga terciptanya efektifitas dan efesiensi proses pemasaran.

Media instagram merupakan salah satu media pemasaran yang sedang banyak digunakan oleh pemasar online (bisnis online) dalam promosi dan pemasaran produknya, hal ini merupakan hal yang wajar mengingat media instagram menjadi salah satu media yang sedang banyak digunakan oleh masyarakat. Begitu pula dengan marketing atau pemasar dalam bisnis clothing line yang tidak mau ketinggalan untuk memanfaatkan media instagram sebagai media promosi dan pemasaran mereka.

Menurut Hanggono (2015) instagram merupakan aplikasi berbagi foto yang dapat dilihat oleh followers dari peng-upload foto tersebut dan dapat saling berkomentar antara sesama pengguna. Nama instagram berasal dari insta dan gram, "insta" yang berasal dari kata instant dan "gram" yang berasal dari telegram, dapat disimpulkan dari namanya yang dapat diartikan menginformasikan atau membagikan foto kepada orang lain dengan cepat dan praktis. sesuatu yang unik dari Instagram adalah foto yang berbentuk persegi, terlihat seperti kamera polaroid dan kodak instamatic bukan seperti foto umumnya yang menggunakan rasio.

Berdasarkan tulisan Movementi, dalam TEMPO.CO (2014) total pengguna 
yang melakukan login di media instagram mencapai 300 juta per bulannya. Sedangkan pengguna aktif per bulannya diklaim berjumlah 284 juta. Jumlah tersebut mengalami peningkatan signifikan. Sebab, pada 2013, pengguna aktif per bulannya hanya 150 juta. Lembaga riset eMarketer menyatakan pengguna Instagram didominasi anak muda berusia 18-24 tahun. "Mayoritas berasal dari luar Amerika Serikat," ujar Washington Post. Artinya, aplikasi tersebut mengalami pertumbuhan yang baik di luar negara asalnya.

Dalam bisnis clothing line di media instagram, lebih mengutamakan orisinalitas dari produk yang dimilikinya, maka dari itu rata-rata para pebisnis clothing line memiliki nama merek mereka sendiri, dimana mereka menjualberbagai macam jenis barang dengan satu merek yang yang sama. Terlihat jelas perbedaan mendasar antar bisnis clothing line dengan bisnis fashionlainya seperti toko pakaian ataupun distributor outlet yang dikenal di kalangan remaja dengan sebutan distro. Jika pada bisnis clothing line menjual berbagai barang fashion dengan satu merk, maka distro menjual berbagai macam barang fashion dengan berbagai macam merk.

Untuk merebut pangsa pasar, para pebisnis clothing line melakukan berbagai cara promosi atau penyampain produk mereka. Mengingat dunia internet atau khususnya dunia bisnis online adalah dunia yang sangat luas dan tentunya juga dunia yang sangat bebas, dimana suatu inovasi yang baru muncul bisa begitu cepat tersebar, di ikuti, serta di amini oleh para kompetitor lainya, dengan begitu inovasi terus berputar dan berkembang.

Dan salah satu proses penyampaian produk yang saat ini sedang menjadi primadona oleh para pebisnis online, khususnya clothing line adalah penggunaan model wanita yang menampilkan kesan seksi serta membawakan suatu produk yang hendak dipasarkan, penggunaan model wanita memang sudah menjadi hal umum, dimana baik iklan di media elektronik maupun media cetak tak luput dan bahkan berlomba-lomba menampilkan iklan mereka secara sensual. Daya tarik wanita memang tidak bisa dipungkiri mampu menjadi penabuh genderang perang dalam proses pemasaran, seketika daya tarik wanita mampu memalingkan perhatian dan seolah berkata "hai ini loh aku!", dan disitulah proses pemasaran dengan cepat dapat masuk dan mengisi ruang kosong dalam fikiran sehingga menimbulkan keingin tahuan yang lebih dalam terhadap suatu produk.

Dalam bisnis clothing line di media instagram seolah semuanya menjadi satu kesatuan yang saling mendukung antara media yang digunakan sebagai media promosi dan strategi yang digunakan dalam promosi, dimana kita tahu bahwa media instagram adalah media sosial yang menampilkan foto-foto atau gambar, dan strategi dengan menampilkan model cantik yang membawakan unsur sensual dalam setiap postingan foto di media instagram dirasa efektif karena otak mampu begitu cepat menerjemahkan tampilan visual, terlebih tampilan visual yang memasukkan unsur sensual sangat cepat dan mampu memberikan gaya tarik tersendiri, terutama bagi kaum laki-laki.

Strategi yang sangat mujarab ini secara sengaja mampu memberikan keuntungan yang begitu besar bagi para pebisnis clothing line di media sosial khusunya instagram, karena para konsumen dengan cepat merespon setiap penyampaian produk kita, namun secara tidak sengaja strategi ini memberikan dampak negatif bagi para konsumen yang belum matang secara pola pikir dan usia, mengingat bisnis di bidang fashion khusunya clothing line tidak mengenal usia dan siapapun bisa terlibat sebagai konsumen.

Tujuan dari penelitian ini di antaranya: 1) untuk mengetahui pengaruh variabel pembawaan model (model performance) terhadap minat beli pada 
produk clothing line Berak di instagram, 2) untuk mengetahui pengaruh variabel bahasa tubuh (body language) terhadap minat beli pada produk clothing line Berak di instagram, 3) untuk mengetahui pengaruh variabel cara berkomunikasi (communicate style) terhadap minat beli pada produk clothing line Berak di Instagram dan 4) untuk mengetahui strategi pemasaran sensual (sensual marketing) yang terdiri dari pembawaan $\left(\mathrm{X}_{1}\right)$, bahasa tubuh $\left(\mathrm{X}_{2}\right)$, cara berkomunikasi $\left(\mathrm{X}_{3}\right)$ berpengaruh secara simultan terhadap minat beli pada produk clothing line Berak di instagram.

\section{REVIEW LITERATUR DAN HIPOTESIS}

\section{Landasan Teori}

\section{Sensual Marketing}

Menurut Ma'mun (2015) sensual marketing bisa dipicu oleh berbagai hal antara lain pembawaan (performance), cara berkomunikasi (communicating style) dan bahasa tubuh (body language). Adapun sub-sub tersebut yaitu:

a. Pembawaan model (model performance) merupakan tampilan fisik yang dapat diindera dengan menggunakan penglihatan.

b. Bahasa tubuh (body language), body language ini lebih mengarah pada gerakan fisik (lemah lembut, tegap, dan lainya).

c. Cara berkomunikasi (communicating style), komunikasi mutlak harus terpenuhi oleh si pembawa karena melalui komunikasi ini akan tercipta interkasi antara konsumen dan endorse (tokoh).

\section{Minat Beli}

Menurut Dwityanti (2008) minat beli adalah tahap kecenderungan responden untuk bertindak sebelum keputusan membeli benar-benar dilaksanakan.

\section{Penelitian Terdahulu}

Penelitian yang menjadi acuan dari penelitian ini adalah penelitian mengenai analisis pengaruh sensual advertising terhadap motivasi pembelian produk susu L-Men di Ratu Super Market Malang yang dilakukan oleh Shofar (2009). Metode penelitian menggunakan Explanatory research, yang meneliti variabel pembawaan, cara berkomunikasi dan bahasa tubuh. Hasil uji regresi linier berganda menunjukkan bahwa, uji ANOVA yang digunakan sebagai uji tingkat kesesuaian model menunjukkan tingkat signifikansi sebesar 0,000 $(\rho<0,05)$. Dengan demikian semua variabel bebas yang terdiri dari pembawaan, cara berkomunikasi, bahasa tubuh dapat menjelaskan variabel terkait (motivasi pembelian) secara bersamasama.

Hasil pengujian koefisien regresi untuk variabel pembawaan $\left(\mathrm{X}_{1}\right)$ menunjukkan bahwa tingkat seignifikansi sebesar $0,382 \quad(\rho>0,05)$ membuktikan bahwa variabel pembawaan tidak berpengaruh terhadap motivasi pembelian. Hasil pengujian koefisien regresi untuk variabel cara berkomunikasi $\left(\mathrm{X}_{2}\right)$ menunjukan bahwa tingkat signifikansi sebesar $0,009 \quad(\rho<0,05) \quad$ membuktikan bahwa variabel cara berkomunikasi berpengaruh terhadap motivasi pembelian. Hasil pengujian koefisien untuk variabel bahasa tubuh $\left(\mathrm{X}_{3}\right)$ menunjukkan bahwa tingkat signifikansi sebesar 0,230 $(\rho>0,05)$ membuktikan bahwa variabel bahasa tubuh tidak berpengaruh terhadap motivasi pembelian.

Sedangkan diantara variabel bebas (pembawaan, cara berkomunikasi, bahasa tubuh) yang memiliki pengaruh dominan terhadap veriabel terkait adalah variabel cara berkomunikasi $\left(\mathrm{X}_{2}\right)$ dengan nilai beta yang telah di standarisasi (Standardized Coefficients) terbesar yaitu sebesar 0,456. 


\section{Hipotesis}

H1: Terdapat pengaruh positif variabel pembawaan $\left(\mathrm{X}_{1}\right)$ terhadap minat beli pada produk clothing line Berak di instagram.

H2: Terdapat pengaruh positif variabel bahasa tubuh $\left(\mathrm{X}_{2}\right)$ terhadap minat beli pada produk clothing line Berak di instagram.

H3: Terdapat pengaruh positif variabel cara berkomunikasi $\left(\mathrm{X}_{3}\right)$ terhadap minat beli pada produk clothing line Berak di instagram.

H4: Terdapat pengaruh positif strategi pemasaran sensual (sensual marketing)yang terdiri dari pembawaan $\left(\mathrm{X}_{1}\right)$, bahasa tubuh $\left(\mathrm{X}_{2}\right)$, cara berkomunikasi $\left(\mathrm{X}_{3}\right)$ berpengaruh secara simultan terhadap minat beli pada produk clothing line Berak di instagram.

METODE PENELITIAN

\section{Populasi dan Sampel}

Menurut Sugiyono (2004) populasi adalah wilayah generalisasi yang terdiri atas obyek/subyek yang mempunyai kualitas dan karateristik tertentu yang ditetapkan oleh peneliti untuk dipelajari kemudian ditarik kesimpulan. Dalam penelitian ini ditetapkan bahwa populasinya adalah mahasiswa perguruan tinggi swasta di kota Yogyakarta yang pernah melihat tampilan instagram Berak.

Menurut Sugiyono (2004) sampel adalah bagian dari jumlah dan karateristik yang dimiliki oleh populasi tersebut. Sampel dari penelitian ini adalah sebagaian mahasiswa dari perguruan tinggi swasta yang ada di Kota Yogyakarta. Mengingat populasi dalam penelitian ini tidak diketahui, maka menurut Isnaeni (2013) besarnya jumlah sampel yang diambil dapat ditentukan dengan cara mengalikan jumlah dengan 5, atau $5 x$ jumlah item variabel. Dalam penelitian ini ada 13 item pertanyaan yang mewakili variabel, jadi jumlah sampel yang dianggap representatif dan mewakili ciri- ciri dari populasi minimal 13 x $5=65$. Dan dalam penelitian ini target sampelnya berjumlah 80 responden, dengan asumsi telah melebihi jumlah sampel minimal yang dibutuhkan.

\section{Definisi Operasional}

1. Variabel Independen

a. Pembawaan Model (X1)

Dimana

pembawaan merupakan ciri khas tersendiri yang ada pada diri model dan sangat mudah di deteksi melalui indra penglihatan atau mata. Dalam penelitian ini item pembawaan yang ada didalamnya di antaranya mimik wajah dan daya tarik fisik. Apabila item mimik wajah dan daya tarik fisik bisa diterima oleh target pasar sebagai suatu sebab yang bisa menarik minat beli mereka, maka indikator pembawaan (performance) yang ditampilkan oleh model clothing line Berak mampu menjadi daya tarik untuk memicu minat beli target pasar.

b. Bahasa Tubuh (X2)

Bahasa tubuh yang ditampilkan oleh model clothing line Berak merupakan tampilan gambar yang dihasilkan dari gerakan model pada saat melakukan pengambilan gambar atau foto. Item pose model merupakan item yang terdapat di dalam variabel bahasa tubuh. Kemampuan berpose model clothing line Berak dengan menggunakan produk yang ingin di jual kepada target pasar bertujuan untuk menarik minat beli target pasar.

c. Cara Berkomunikasi (X3)

Cara berkomunikasi yang dimaksud dalam penelitian ini adalah variabel yang berhubungan dengan tampilan videogram yang ada pada akun instagram dari produk clothing line Berak. Dalam tampilan video ini, clothing line Berak lebih mengexplore isu-isu sensual yang mereka tonjolkan. Tampilan 
videogram bisa menjadi pemicu minat beli konsumen jika maksud dari proses penyampaian ini bisa diterima dan ditangkap dengan baik oleh target pasar.

\section{Variabel Dependen}

$$
\text { Menurut Sugiyono (2004) }
$$
variabel dependen sering disebut sebagai variabel output, kriteria, konsekuen. Dalam bahasa Indonesia sering disebut sebagai variabel terikat. Variabel terikat merupakan variabel yang dipengaruhi atau yang menjadi akibat, karena adanya variabel bebas, variabel terkait dalam penelitian ini yaitu minat beli.

\section{Uji Instrumen}

\section{Uji Validitas}

Menurut Sugiyono (2004) instrument yang valid berarti alat ukur yang digunakan untuk mendapatkan data (mengukur) itu valid. Valid berarti instrument tersebut dapat digunakan untuk mengukur apa yang seharusnya diukur. Analisis faktor adalah salah satu analisis yang bisa digunakan sebagai alat ukur tingkat validitas suatu data, dimana indikator yang dikatakan valid jika hanya terbentuk satu kompenen, yang artinya indikatorindikator tersebut hanya menjelaskan satu faktor saja.

\section{Uji Reliabilitas}

Instrumen yang reliabel menurut Sugiyono (2004) adalah instrumen yang bila digunakan beberapa kali untuk mengukur obyek yang sama, akan menghasilkan data yang sama. Uji reliabilitas untuk alternatif jawaban lebih dari dua menggunakan uji cronbach's alpha, yang nilainya akan dibandingkan dengan nilai koefisien reliabilitas minimal yang dapat diterima. Reliabilitas kurang dari 0.6 adalah kurang baik, sedangkan 0.7 dapat diterima, dan lebih dari 0.8 adalah baik. Menurut Saidani (2012) jika nilai nilai cronbach's alpha $>0.6$, maka instrumen penelitian reliabel. Jika nilai cronbach's alpha $<0.6$, maka instrumen penelitian tidak reliabel.

\section{Teknik Analisis Data}

1. Analisis Regresi Berganda

$$
\begin{aligned}
& Y=a+b 1 \cdot X_{1}+b 2 \cdot X_{2}+b 3 \cdot X_{3} \\
& \text { Dimana: } \\
& Y=\text { Minat Beli } \\
& a=\text { Konstanta } \\
& \text { b1, b2, b3 = Koefisien regresi } \\
& X_{1}=\text { Pembawaan } \\
& X_{2}=\text { Bahasa tubuh } \\
& X_{3}=\text { Cara Berkomunikasi }
\end{aligned}
$$

\section{Uji Hipotesis}

\section{Uji Parsial (Uji T)}

Uji $t$ atau uji parsial adalah pengujian variabel bebas (pembawaan model, bahasa tubuh, dan cara berkomunikasi) terhadap variabel terkait (minat beli) secara sendirisendiri dengan taraf signifikansi sebesar $5 \%$. Dengan syarat jika nilai signifikansi $(p<0.05)$ maka H0 ditolak dan $\mathrm{Ha}$ diterima, dan jika $(\mathrm{p}>0.05)$ maka Ha ditolak dan $\mathrm{HO}$ diterima.

\section{Uji Simultan (Uji F)}

Uji $F$ atau uji simultan adalah pengujian variabel bebas (pembawaan model $\mathrm{X}_{1}$, bahasa tubuh $\mathrm{X}_{2}$, dan cara berkomunikasi $\mathrm{X}_{3}$ ) terhadap variabel terkait (minat beli Y) secara bersamasama. Bila nilai signifikansi $(p<0.05)$ maka Ho ditolak dan Ha diterima, artinya semua veriabel bebas secara bersama-sama merupakan penjelas yang signifikan terhadap variabel terikat, dengan taraf signifikansi 5\%.

\section{Uji Koefisien Determinasi}

Koefisien determinasi $\left(\mathrm{R}^{2}\right)$ digunakan untuk mengukur seberapa jauh kemampuan model dalam menerangkan variasi variabel dependen. Menurut Dewa (2009:32) nilai $\mathrm{R}^{2}$ berkisar antara $0<\mathrm{R}^{2}<1$. 


\section{HASIL PENELITIAN DAN PEMBAHASAN}

\section{Hasil Analisis Responden}

Karakteristik Responden Berdasarkan Jenis Kelamin

\begin{tabular}{|c|c|c|c|}
\hline No. & Jenis Kelamin & Jumlah & $\begin{array}{c}\text { Prosentase } \\
(\%)\end{array}$ \\
\hline 1 & Laki-laki & 54 & $67,5 \%$ \\
\hline 2 & Perempuan & 26 & $32,5 \%$ \\
\hline & Total & 80 & $100 \%$ \\
\hline
\end{tabular}

Dari tabel di atas dapat dilihat bahwa mayoritas responden dari penelitian ini adalah responden laki-laki. Hal ini dapat dilihat dengan jumlah responden laki-laki sebesar 54 responden $(67,5 \%)$, sedangkan jumlah responden perempuan sebesar 26 responden $(32,6 \%)$ dari total 80 responden yang menjadi objek penelitian.

Karakteristik Responden Berdasarkan Jumlah Uang Saku Per-Bulan

\begin{tabular}{|c|c|c|c|}
\hline No. & Uang saku per bulan & Jumlah & Prosentase (\%) \\
\hline 1 & $<1$ juta & 26 & $32,5 \%$ \\
\hline 2 & $1-3$ juta & 50 & $62,5 \%$ \\
\hline 3 & $>3$ juta & 4 & $5 \%$ \\
\hline \multicolumn{2}{|r|}{ Total } & 80 & $100 \%$ \\
\hline
\end{tabular}

Dari tabel dia atas dapat dilihat bahwa jumlah responden yang memiliki uang saku per bulan kurang dari 1 juta sebanyak 26 responden dengan prosentase sebesar 32,5\%. Sedangkan jumlah responden dengan uang saku perbulan sebesar 1-3 juta sebanyak 50 responden dengan prosentase sebesar 62,5\%. Dan jumlah responden dengan uang saku lebih dari 3 juta per bulan sebanyak 4 responden dengan prosentase sebesar $5 \%$.

\section{Hasil Penelitian}

1. Hasil Uji Validitas

\begin{tabular}{|c|c|c|c|c|c|}
\hline \multicolumn{6}{|c|}{ Hasil Uji Validitas } \\
\hline \multirow{2}{*}{$\begin{array}{c}\text { Item } \\
\text { Variabel }\end{array}$} & \multicolumn{4}{|c|}{ Variabel } & \multirow[b]{2}{*}{ Keterangan } \\
\hline & $\begin{array}{c}\text { Pembawaan } \\
\text { Model }\end{array}$ & $\begin{array}{l}\text { Bahasa } \\
\text { Tubuh }\end{array}$ & $\begin{array}{c}\text { Cara } \\
\text { Berkomunikasi }\end{array}$ & $\begin{array}{c}\begin{array}{c}\text { Minat } \\
\text { beli }\end{array} \\
\end{array}$ & \\
\hline P1 & 0.799 & & & & \multirow{5}{*}{ Valid } \\
\hline P2 & 0.803 & & & & \\
\hline P3 & 0.716 & & & & \\
\hline P4 & 0.638 & & & & \\
\hline P5 & 0.728 & & & & \\
\hline BI & & 0.914 & & & \multirow{2}{*}{ Valid } \\
\hline B2 & & 0.914 & & & \\
\hline Cl & & & 0.932 & & \multirow{2}{*}{ Valid } \\
\hline $\mathrm{C} 2$ & & & 0.932 & & \\
\hline M1 & & & & 0.804 & \multirow{4}{*}{ Valid } \\
\hline M2 & & & & 0.880 & \\
\hline M3 & & & & 0.897 & \\
\hline M4 & & & & 0.785 & \\
\hline
\end{tabular}

Dilihat dari hasil tabel di atas bahwa semua komponen indikator kuesioner mengelompok pada variabelnya masing-masing, dengan demikian berarti semua komponen indikator kuesioner dikatakan valid.

2. Hasil Uji Reliabilitas

\begin{tabular}{|l|l|c|c|}
\multicolumn{5}{|l}{ Hasil Uji Reliabilitas } \\
\hline Nama Variabel & \multicolumn{2}{l|}{ Nilai Cronbach Alpha } & Keterangan \\
\hline Pembawaan Model & 0,774 & 0,6 & Reliabel \\
\hline Bahasa Tubuh & 0,792 & 0,6 & Reliabel \\
\hline Cara Berkomunikasi & 0,841 & 0,6 & Reliabel \\
\hline Minat Beli & 0,861 & 0,6 & Reliabel \\
\hline
\end{tabular}

Dilihat dari tabel di atas dapat dilihat bahwa semua variabel baik variabel independen (pembawaan model, bahasa tubuh, cara berkomunikasi) maupun variabel dependen (minat beli) dinyatakan reliabel, karena nilai Cronbach alpha lebih dari 0,6. 
3. Hasil Uji Regresi Linier Berganda Hasil Uji Regresi Linie Berganda

\begin{tabular}{|c|c|}
\hline Model & $\boldsymbol{B}$ \\
\hline Constant & -.469 \\
\hline Pembawaan Model & .433 \\
\hline Bahasa Tubuh & .423 \\
\hline Cara Berkomunikasi & .462 \\
\hline
\end{tabular}

$\mathrm{Y}=(-0,469)+0,433 \mathrm{X}_{1}+0,423 \mathrm{X}_{2}+$ $0,462 X_{3}$

Dari hasil analisis tersebut, maka dapat dijelaskan sebagai berikut:

Nilai konstanta sebesar $-0,469$ yang berarti variabel minat beli akan konstan sebesar $-0,469$ jika tidak adanya atau sebelum adanya pengaruh dari variabel independen, dalam hal ini variabel pembawaan model $\left(\mathrm{X}_{1}\right)$, Bahasa tubuh $\left(\mathrm{X}_{2}\right)$, dan variabel cara berkomunikasi $\left(\mathrm{X}_{3}\right)$.

Variabel pembawaan model $\left(\mathrm{X}_{1}\right)$ berpengaruh positif terhadap variabel motivasi pembelian sebesar 0,433. Artinya jika variabel pembawaan model dinaikkan 1 satuan maka variabel minat beli akan naik sebesar 0,433. Sebaliknya jika variabel pembawaan model diturunkan sebesar 1 satuan maka variabel minat beli akan turun sebesar 0,433. Dengan asumsi variabel bebas lainya $\mathrm{X}_{2}, \mathrm{X}_{3}=0$ atau Cateris Paribus.

Variabel Bahasa tubuh $\left(\mathrm{X}_{2}\right)$ berpengaruh positif terhadap variabel motivasi pembelian sebesar 0,423. Artinya jika variabel Bahasa tubuh dinaikkan 1 satuan maka variabel minat beli akan naik sebesar 0,423. Sebaliknya jika variabel Bahasa tubuh diturunkan sebesar 1 satuan maka variabel minat beli akan turun sebesar 0,423 . Dengan asumsi variabel bebas lainya $\mathrm{X}_{1}, \mathrm{X}_{3}=0$ atau Cateris Paribus.

Variabel cara berkomunikasi $\left(\mathrm{X}_{3}\right)$ berpengaruh positif terhadap variabel motivasi pembelian sebesar 0,462. Artinya jika variabel cara berkomunikasi dinaikkan 1 satuan maka variabel minat beli akan naik sebesar 0,462 . Sebaliknya jika variabel cara berkomunikasi diturunkan sebesar 1 satuan maka variabel minat beli akan turun sebesar 0,462. Dengan asumsi variabel bebas lainya $\mathrm{X}_{1}, \mathrm{X}_{2}=0$ atau Cateris Paribus.

\section{Hasil Uji Parsial (Uji T)}

Hasil Uji T (Parsial)

\begin{tabular}{|c|c|c|l|}
\hline Variabel & \multicolumn{2}{|c|}{ Sig. } & Keterangan \\
\hline Pembawaan Model & .000 & 0,05 & Signifikan \\
\hline Bahasa tubuh & .016 & 0,05 & Signifikan \\
\hline Cara Berkomunikasi & .020 & 0,05 & Signifikan \\
\hline
\end{tabular}

Berdasarkan tabel di atas dapat dilihat bahwa variabel bebas pembawaan model $\left(\mathrm{X}_{1}\right)$ memiliki tingkat signifikansi sebesar 0.000 $(p<0.05)$ membuktikan bahawa variabel pembawaan model $\left(\mathrm{X}_{1}\right)$ mempengaruhi variabel minat beli (Y). Variabel bahasa tubuh $\left(\mathrm{X}_{2}\right)$ yang mempunya tingkat signifikansi sebesar $0.016 \quad(p<0.05)$ membuktikan bahwa variabel bahasa tubuh $\left(\mathrm{X}_{2}\right)$ mempengaruhi variabel minat beli (Y). Dan juga variabel cara berkomunikasi $\left(\mathrm{X}_{3}\right)$ yang mempunyai tingkat signifikansi sebesar 0.020 $(p<0.05)$ membuktikan bahwa variabel cara berkomunikasi $\left(\mathrm{X}_{3}\right)$ mempengaruhi variabel minat beli $(\mathrm{Y})$.

5. Hasil Uji Simultan (Uji F)

\begin{tabular}{|c|c|c|}
\multicolumn{3}{c}{ Hasil Uji F (ANOVA) } \\
\hline Model & sig & Keterangan \\
\hline Regression & 0,000 & Signifikan \\
\hline
\end{tabular}

Pengujian secara simultan adalah pengujian pengaruh variabel pembawaan model $\left(\mathrm{X}_{1}\right)$, bahasa tubuh $\left(\mathrm{X}_{2}\right)$, dan cara berkomunikasi $\left(\mathrm{X}_{3}\right)$ 
terhadap variabel minat beli $(\mathrm{Y})$ secara bersama-sama. Berdasarkan tabel di atas dapat dilihat bahwa tingkat signifikansi sebesar $0.000 \quad(p<0.05)$ yang berarti variabel independen yang terdiri dari pembawaan model $\left(\mathrm{X}_{1}\right)$, bahasa tubuh $\left(\mathrm{X}_{2}\right)$, dan cara berkomunikasi $\quad\left(\mathrm{X}_{3}\right) \quad$ mampu mempengaruhi variabel minat beli (Y) secara bersama-sama.

6. Hasil Uji Koefisien Determinasi

Hasil Uji $\mathbf{R}^{2}$

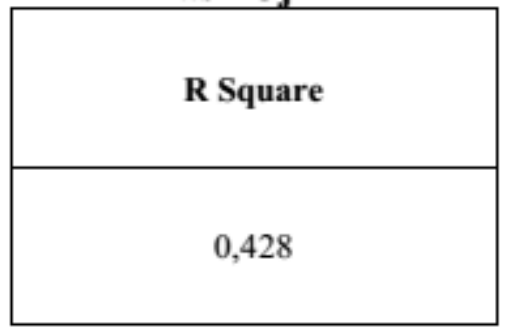

Berdasarkan tabel di atas dapat dilihat nilai $\mathrm{r}$ squaresebesar 0.428 atau $42.8 \%$. Yang berarti kemampuan variabel independen (X) dalam menjelaskan variabel dependen (Y) sebesar $42.8 \%$ sedangkan sisanya sebesar 57,2 \% dipengaruhi oleh variabel lain yang tidak terdapatdalam penelitian ini.

\section{Pembahasan}

1. Pengaruh Pembawaan Model (Model Performance), Bahasa Tubuh (Body Language), Cara Berkomunikasi (Communicate Style) Secara Parsial Terhadap Minat Beli.

a. Variabel Pembawaan Model (Model Performance)

Berdasarkan tabel di atas dapat dilihat bahawa nilai t-hitung unutuk variabel bebas pembawaan model $\left(\mathrm{X}_{1}\right)$ adalah sebesar 4.785 dengan tingkat signifikansi sebesar $0.000 \quad(p<0.05) \quad$ membuktikan bahawa variabel pembawaan model $\left(\mathrm{X}_{1}\right)$ yang terdiri dari item mimik wajah dan daya tarik fisik bisa diterima oleh target pasar sebagai suatu sebab yang bisa menarik minat beli mereka. b. Variabel Bahasa Tubuh (Body Language)

Variabel bahasa tubuh $\left(\mathrm{X}_{2}\right)$ yang mempunya nilai t-hitung sebesar 2.460 dengan tingkat signifikansi sebesar $0.016(\mathfrak{p}<0.05)$ membuktikan bahwa variabel bahasa tubuh $\left(\mathrm{X}_{2}\right)$ yang terdiri dari itempose model bisa diterima oleh target pasar sebagai suatu sebab yangbisa menarik minat beli mereka.

c. Variabel Cara Berkomunikasi (Communicate Style)

Dan juga variabel cara berkomunikasi $\left(\mathrm{X}_{3}\right) \quad$ yang mempunyai nilai t-hitung sebesar 2.382 dengan tingkat signifikansi sebesar $0.020(p<0.05)$ membuktikan bahwa variabel cara berkomunikasi $\left(\mathrm{X}_{3}\right)$ yang terdiri dari item tampilan videogram bisa menjadi pemicu minat beli konsumen dan maksud dari proses penyampaian ini bisa diterima dan ditangkap dengan baik oleh target pasar.

2. Pengaruh Pembawaan Model (Model Performance), Bahasa Tubuh (Body Language), Cara Berkomunikasi (Communicate Style) Secara simultan Terhadap Minat Beli.

Berdasarkan hasil uji $\mathrm{F}$ yang ada pada tabel di atas menunjukkan tingkat signifikansi sebesar $0.000(p<0.05)$ yang berarti bahwa $\mathrm{Ha}$ diterima sedangkan $\mathrm{H} 0$ ditolak. Ini sekaligus menunjukkan bahwa sensual marketing yang terdiri dari variabel pembawaan model $\left(\mathrm{X}_{1}\right)$, bahasa tubuh $\left(\mathrm{X}_{2}\right)$, dan cara berkomunikasi $\left(\mathrm{X}_{3}\right)$ secara simultan memiliki pengaruh yang signifikan terhadap variabel minat beli (Y). 


\section{KESIMPULAN DAN SARAN}

\section{Kesimpulan}

1. Secara simultan variabel independen yang terdiri dari variabel pembawaan model $\left(\mathrm{X}_{1}\right)$, bahasa tubuh $\left(\mathrm{X}_{2}\right)$, dan cara berkomunikasi $\left(\mathrm{X}_{3}\right)$ berpengaruh signifikan terhadap variabel minat beli (Y), yang merupakan variabel dependen. Hal ini dapat dilihat dari tingkat signifikansi sebesar $0.000(p<$ 0.05), hal ini sejalan dengan hipotesa yang menyebutkan bahwa terdapat pengaruh yang positif strategi pemasaran sensual (sensual marketing) yang terdiri dari pembawaan $\left(\mathrm{X}_{1}\right)$, bahasa tubuh $\left(\mathrm{X}_{2}\right)$,cara berkomunikasi $\left(\mathrm{X}_{3}\right)$ secara simultan terhadap minat beli pada produk clothing line Berak di instagram.

2. Secara parsial semua variabel independen $(\mathrm{X})$ berpengaruh signifikan terhadap variabel dependen (Y). hal ini dibuktikan dengan tingkat signifikansi yang dimiliki masing-masing variabel independen diantaranya:

a. Variabel pembawaan model $\left(\mathrm{X}_{1}\right)$ memiliki tingkan signifikansi sebesar $0.000(p<0.05)$.

b. Variabel bahasa tubuh $\left(\mathrm{X}_{2}\right)$ mempunyai tingkat signifikansi sebesar $0.016(p<0.05)$.

c. Variabel cara berkomunikasi $\left(\mathrm{X}_{3}\right)$ yang mempunyai tingkat signifikansi sebesar $0.020(p<0.05)$. Hal ini sejalan dengan hipotesa yang menyebutkan bahwa terdapat pengaruh yang positif variabel independen (X) terhadap variabel dependen (Y) secara parsial pada produk clothing line "Berak" di Instagram.

\section{Saran}

1. Peneliti Selanjutnya

Dengan kesadaran penulis bahwa penelitian ini belum sepenuhnya sempurna, dan dengan dasar bahwa keharusan untuk selalu memperkaya sebuah penelitian, agar dapat digunakan oleh semua pihak yang terkait. Peneliti berharap agar penelitian selanjutnya lebih memperdalam obyek penelitian, dan menambahkan variabel sensual marketing lainnya yang tidak tercantum atau tidak dimasukkan pada penelitian ini.

2. Owner Produk Clothing Line "Berak"

Agar produk "Berak" selalu mendapatkan tempat di hati konsumen dan mampu meningkatkan jumlah peminat, tentunya cara penyampaian produk harus tetap dipertahankan, dengan catatan terus berinovasi dalam sektor diluar strategi penyampaian produk. Misalnya saja dalam hal pelayanan konsumen dan kualitas produk, karena tidak bisa kita pungkiri bahwa strategi sensual marketing hanyalah sebagai strategi penyampaian produk untuk mengalihkan pandangan target pasar.

Penulis juga berharap agar owner produk clothing line "Berak" lebih memperhatikan etika serta batasan yang sewajarnya dalam penerapan strategi sensual marketing sebagai strategi penyampaian produk. Meskipun strategi sensual marketingadalah strategi yang efektif namun disisi lain merupakan strategi yang cukup "liar". Maka dari itu perlunya memperhatikan batasan yang sewajarnya agar tidak menyalahi norma yang ada dalam masyarakat.

\section{DAFTAR PUSTAKA}

Dwityanti, Esthi. (2008). “Analisis Faktorfaktor Yang Mempengaruhi Minat Beli Konsumen Terhadap Layanan Internet Banking Mandiri, Studi 
Kasus Pada Karyawan Departemen

Pekerjaan Umum Jakarta”. Tesis.

Hanggono, Aditya Arie, Handayani, Siti

Ragil, dan Susilo, Heru. (2015).

"Analisis Atas Praktek Tam

(Technology Acceptance Model)

Dalam Mendukung Bisnis Online

Dengan Memanfaatkan Jejaring

Sosial Instagram”. Jurnal

Administrasi Bisnis, Vol.12.

Ma'mun, Syukron. (2015). "Sensual

Marketing (Memasarkan Produk

Dengan Menggunakan JasaSales

Promotion Girls) Menurut

Perespektif Ekonomi Islam, Studi

Kasus Pada PT. Smartfren Telekom

Cabang Semarang". Skripsi.

Movementi, Satwika. 12 Desember 2004.

"Pengguna Instagram Capai 300 juta". Tempo.co.

Saidani, Basrah dan Arifin, Samsul. (2012). "Pengaruh Kualitas Produk dan Kualitas Layanan Terhadap Kepuasan Konsumen dan Minat Beli Pada Ranch Market". Jurnal Riset Manajemen Sains Indonesia (JRMSI) Vol 3, No.1, 2012.

Shofar, Abidah Alen. (2009). "Pengaruh

Strategi Sensual Advertising Media Telivisi Terhadap Motivasi Pembelian Produk Susu L-Men Di Ratu Super Market Malang”. Skripsi.

Sugiyono. (2004). Metode Penelitian Bisnis. Bandung: Alfabeta.

Utami, Agustin Dyah dan Triyono, Ramadian Agus. (2011). "Pemanfaatan Blackberry Sebagai Sarana Komunikasi Dan Penjualan Batik Online Dengan Sistem Dropship Di Batik Solo 85". Journal Speed-Sentra Penelitian Engineering dan Edukasi - Volume 3 No 3, 2011. 